\title{
The Research on the Construction of Entrepreneurial Practice Platform for Undergraduates in Agricultural colleges and Universities
}

\author{
Xiaodong Qin ${ }^{1, a}$, Danhe Zhang ${ }^{2, b}$ \\ ${ }^{1}$ School of Jilin Agricultural University, Changchun 130118 , China ; \\ ${ }^{2}$ School of The Tourism College of Changchun University, Changchun 130607 , China. \\ a44513130@qq.com; ${ }^{b} 65094205 @ q q . c o m$
}

Keywords: agricultural colleges and universities; entrepreneurial practice platform for undergraduates

\begin{abstract}
Entrepreneurial practice platform for undergraduates is the organic carrier of college students' entrepreneurial practice and the main position of the practice of entrepreneurial education. This paper takes the entrepreneurial practice platform for undergraduates in agricultural colleges and universities as the research object. Through the investigation, this paper analyzes the current situation and existing problems of this platform, and finally puts forward some rational suggestions for the construction and development of this platform.
\end{abstract}

\section{Introduction}

With the deepening of entrepreneurship education, the construction of entrepreneurial practice platform for undergraduates is particularly important, as the practice carrier of undergraduates 'entrepreneurship education. Research and practice platform in agricultural colleges and universities has rich resources, and is very close to the actual agricultural production, which creates a lot of new agricultural varieties and agricultural machinery innovation. How to make good use of these entrepreneurial practice platforms, promote undergraduates' entrepreneurship in their respective fields, and form a joint force between these platforms to promote the development of entrepreneurship education is an urgent problem to be solved.

\section{The Connotation of Entrepreneurial Practice Platform for Undergraduates}

\subsection{The Definition of Entrepreneurial practice platform for undergraduates}

Entrepreneurial practice platform is based on the actual operating capacity, aims at shaping or improving the practical ability of entrepreneurship, summarizes and integrates the advantages of entrepreneurial resources and applies them to the entrepreneurial practice of the management model or operating system. Entrepreneurial Practice Platform for Undergraduates in Agricultural colleges and Universities generally includes scientific research platform, national provincial and ministerial level experimental center, pilot plant, teaching experimental base, public space, undergraduates entrepreneurship and other platforms.

2.2 The Function of Entrepreneurial Practice Platform for Undergraduates

Entrepreneurial Practice Platform for Undergraduates has the functions of enhancing students' understanding of entrepreneurial theory knowledge, stimulating entrepreneurial enthusiasm, enhancing entrepreneurial ability and accumulating entrepreneurial experience, etc. Through participating in innovation, project practice, product marketing and other entrepreneurial practice activities, undergraduates can combine the theoretical knowledge with practice, deepen their understanding of entrepreneurial theoretical knowledge, and truly apply their knowledge into practice.

2.3 The Classification of Entrepreneurial Practice Platform for Undergraduates

Generally speaking, the entrepreneurial practice platform for undergraduates mainly has the 
following four categories. Firstly, teaching and research practice platform, mainly engaged in practical teaching and scientific research. Through participating in the teaching and research activities of teachers, students can produce innovative products or innovative models, and then to promote or market them to achieve entrepreneurial practice. Secondly, the Pioneer Park and the entrepreneurship base platform, which provides entrepreneurial practice counseling, entrepreneurial incubation and other practical sites. Thirdly, universities and enterprises cooperate to establish the incubator, "public space" and other practical platforms. Fourthly, entrepreneurial service platform, exists in the form of community organizations, provide practice opportunities, practice resources for undergraduates entrepreneurial practice.

\section{The Current Situation of Entrepreneurial Practice Platform for Undergraduates in Agricultural colleges and Universities}

3.1 Large Number of Entrepreneurial Practice Platform for Undergraduates and Low Entrepreneurial Practice Utilization Rate

Although agricultural colleges and universities have more practice platforms, most of them are based on scientific research and teaching activities, while many inventions have great potentials, but lack of practice and promotion, and the number of college students participating in the practice is small. Many new technologies and inventions are buried in the laboratory. Some Pioneer Parks in the colleges and universities basically provide sites, but lack of counseling and incubation. Entrepreneurial activities carried out by student entrepreneurship associations are basically based on counseling reports and entrepreneurship plan, the number of practical entrepreneurial activity and participants is limited. Although there is a wealth of entrepreneurial practice resources, the overall utilization rate is not high and the joint force of entrepreneurship does not play well.

3.2 Lacking of Entrepreneurial Faculty and Tutor Guidance

Faculty of agricultural colleges and universities mainly reflected in the theoretical teaching and research topics, but as for the practical operation of the entrepreneurial guidance, the faculty is weak and the degree of specialization is not high. There are many experts and scholars in the entrepreneurial practice platform, but they lack of the understanding of entrepreneurial field and the practical entrepreneurial guidance for students, so they can only provide limited help for undergraduates in the entrepreneurial practice. Some colleges and universities equip instructors for the practice projects in the entrepreneurial park and some entrepreneurial community equip the corresponding instructor, but because of lacking instructors and the incomplete corresponding system and management system, the entrepreneurship practice is not rich.

3.3 Lack of development platform for the entrepreneurial practice outside school and the capacity of integrating resources.

Agricultural institutions have a lot of enterprise resources and practice sets, which have close ties with the entrepreneurial space and incubators founded by government and entrepreneurs. Many agricultural institutions will limit the entrepreneurial practice in the school, but institutions can only provide limited entrepreneurial information resources and incubation, which results in lacking of entrepreneurial practice platforms and effective entrepreneurial practice. While the enterprises have rich resources of entrepreneurial practice platform and need more entrepreneurs and start - ups, colleges and universities should make full use of social entrepreneurial practice platforms to expand channels of entrepreneurial practice platform for undergraduates.

3.4 Lack of Hardware Construction and Sustained Financial Support

Many colleges and universities give the function of entrepreneurial practice to scientific research platform, practice base, Pioneer Park and other space, but most of the platforms are still at the level of hanging signs and organizing activities, there is no scientific and rational planning for the construction and development of platforms. Platforms lack of necessary hardware facilities and special funds, which results in the stagnation of development of entrepreneurial practice platform. 


\section{Suggestions and Countermeasures on Scientific Construction of Entrepreneurial Practice Platform for Undergraduates in Agricultural Colleges and Universities}

4.1 Make Full Use of Entrepreneurship Practice Platform in Sound Management Institutions and Scientific Classification

The healthy development of the entrepreneurial practice platform in agricultural colleges and universities is inseparable from the sound management institution, perfect management system, and scientific and reasonable operation mechanism. The school should be responsible for the overall planning and macro leadership of undergraduates' entrepreneurial practice platform, and establish the innovation practice system based on the platform's property and function. For the teaching and research platform, the school should actively encourage undergraduates to participate in scientific research practice, and carry out entrepreneurial practice which is in the direction of scientific research. Undergraduates in Shenyang Agricultural University use the school's food science research platform to invent lipid-lowering products through scientific research and practice, test and promote the new products, and establish a company to achieve entrepreneurial practice. Therefore, the school should combine platform features, play platform advantages, integrate resources, and be targeted to carry out the entrepreneurial practice.

4.2 Strengthen the Construction of Entrepreneurial Instructors to Provide Professional Guidance Instructors for Entrepreneurial Practice Platform

Strengthen the construction of entrepreneurial practice platform in agricultural colleges and universities, it is necessary to provide high-quality and relatively stable entrepreneurial guidance instructor to help undergraduates' entrepreneurial practice. The school should improve the method of teacher selection. It should follow the principle of combination of external selection and internal cultivation, and establish a team of full-time and part-time entrepreneurial instructors, so as to improve the practical guidance ability of entrepreneurial instructors through multi-channel cultivating and training. According to actual needs, the school should equip instructors with different entrepreneurial practice platform, so that students can really receive guidance and help in the course of practice.

4.3 Strengthen Communication and Collaboration with Outside Enterprises to Expand the Platform

Pay full attention to communication and collaboration with enterprises, build entrepreneurial practice base with enterprises, and provide students with entrepreneurial practice stage with the resources and strength of enterprises. For example: Jilin Agricultural University establish the entrepreneurial practice base in the Borui feed company, set the topic and carry out research and practice combined with the actual production and sales, , not only solve the problems encountered in production practice but also cultivate students entrepreneurial practice ability through entrepreneurial practice.

4.4 Strengthen the Support of Entrepreneurial Associations and Carry Out Entrepreneurial Practice

Strengthen the support of entrepreneurial associations with providing professional guidance instructors and financial and policy support to help students really improve their entrepreneurial practice ability and accumulate entrepreneurial experience through participating in the entrepreneurial practice. KAB Entrepreneurship Club of Shenyang Agricultural University held marketing contests and other practical activities, and greatly improved the undergraduates' understanding of entrepreneurship and practical ability through entrepreneurial practice.

4.5 Make full use of agricultural practice resources and enrich the practice platform

For agricultural colleges and universities, they should use agricultural resources rationally and efficiently to undergraduates' entrepreneurial practice to play their advantages. For example, Jilin Agricultural University Base Management Office provide six greenhouses for undergraduates, so that undergraduates can do the $\mathrm{R} \& \mathrm{D}$ practice of fruits and vegetables. Students can really understand the joy and harvest of agricultural entrepreneurship through experiencing the cultivation of agricultural products, management, marketing and the whole process, so as to let undergraduates like agriculture, take root in agriculture, and cultivate more innovative talents for agriculture. 


\section{Summary}

In short, the construction of college students 'entrepreneurship practice platform is the key to college students' entrepreneurship practice education. Only by combining entrepreneurship education with entrepreneurial practice, and by combining entrepreneurial practice platform with the group of university students with bold enterprising ability, can the breadth and depth of platform be continuously expanded, can the advantages of agricultural colleges and universities be played , so that truly train outstanding agricultural innovation talent for country.

\section{References}

[1] Gao Hanfeng. Research and Practice on Constructing Agricultural University Students' Innovative and Enterprising Platform. Journal Publishing Department of Agricultural University of Hebei (Agriculture and Forestry Education),2013,12.

[2] Peng Wei. Research and Practice on the Construction of Entrepreneurship Practice Platform for IT Majors. Journal of Hebei Software Institute, 2012,9.

[3] Xu Bohan. Thinking on the Development of Innovative and Enterprising Associations. Journal of Innovation and Enterprise Education, 2012, 8.

[4] Zhang Chen, Construction of Practice Platform for University Students' Innovation and Entrepreneurship. Research and Exploration in Laboratory, 2013,11.

[5]Diao Jia, On the Construction of University Students' Practice Platform. Higher Education Press, 2012,3. 